\title{
Seasonal comparison of ice-surface structures in the ablation area of Jakobshavn Isbræ drainage system, West Greenland
}

\author{
Ute Ghristina HeRZFELD, ${ }^{1,2,3}$ Helmut MAYER ${ }^{3,4}$ \\ ${ }^{1}$ Cooperative Institute for Research in Environmental Sciences, University of Colorado, Boulder, CO 80309-0449, U.S.A. \\ E-mail:herzfeld@tryfan.colorado.edu \\ ${ }^{2}$ Geomathematik, Universität Trier, D-54286 Trier, Germany \\ ${ }^{3}$ Institute of Arctic and Alpine Research, University of Colorado, Boulder, CO 80309-0450, U.S.A. \\ ${ }^{4}$ Institut für Mechanik, Technische Universität Darmstadt, D-64289 Darmstadt, Germany
}

\begin{abstract}
Ice surface roughness is a parameter of importance to many glaciological studies. Surface roughness, a derivative of microtopography, provides the high-resolution information necessary to characterize morphological types of ice surfaces and complements satellite data in investigations of surface features across scale. There has been a gap in observational scale between high-resolution satellite data, aircraft data and analyses at microscopic scale, the latter investigating material properties rather than micromorphology. To fill this gap, we designed and built the Glacier Roughness Sensor (GRS), a towed instrument that collects surface roughness data mechanically in swathsurvey style with $0.1 \mathrm{~m}$ along-track spacing, $0.2 \mathrm{~m}$ across-track spacing, and sub-centimeter accuracy for areas typically $100 \mathrm{~m}$ by $175 \mathrm{~m}$. As a result of this instrument development, the variable ice surface roughness has been added as a geophysical observable in the study of glaciers and ice sheets. The method utilized for analysis of GRS surface roughness data is geostatistical classification employing a range of parameters extracted from vario functions, which are generalized spatial structure functions. In a seasonal comparison of data from spring (May 1997) and summer (late July 1999), characteristic parameters of the spring and summer ice surface were calculated, and, as a result, an answer to the morphogenetic question of ice surface processes could be derived: in this part of the Jakobshavn Isbræ drainage basin, ice-surface structures develop in an interplay of ablation, refreezing, snowfall, wind and (distant) crevassing, each process yields characteristically different components of the surface structure, and ablat ion is the dominant morphogenetic process.
\end{abstract}

\section{INTRODUCTION}

The world's ice sheets and glaciers play an important role in the global climatic system. Not only the large ice sheets of Greenland and Antarctica and the sea-ice cover, but also small glaciers may contribute significantly to sea-level changes in the event of a change in temperature (Meier, 1984). The polar ice caps and the Greenlandic inland ice shield are very sensitive to changes in temperature.

In principle, there are two processes that may cause mass loss in the large ice sheets: (1) break-up (dynamic process), and (2) ablation (climatically induced process); the two may interact. Fast-moving glaciers and ice streams present weakness points in the stability of an ice sheet, and locations where break-up is expected to start. Scenarios for dynamic instabilities have been discussed in Hughes (1973), Clarke and others (1977), Schubert and Yuen (1981), Alley and Whillans (1991) and Huybrechts (1993), among others.

Since the Greenland ice sheet is located in a relatively warm climate, it is particularly sensitive to changes in temperature. Data collected under the Program for Arctic Regional Climate Assessment (PARCA) indicate an increase in temperature of $2{ }^{\circ} \mathrm{C}$ on the central Greenland Inland Ice from the standard decade 1951-60 to 1995-99 (Steffen and Box, 2001). A surface lowering in some of the marginal areas of the Greenland ice sheet has been observed from airborne laser altimeter data (Krabill and others, 1999). Changes in the extent and surface structure of the ablation area of the Greenland ice sheet are indicators of the response of the ice sheet to temperature change, but little is known about regional variability. Large-scale approaches to monitor elevation changes from satellite radar altimetry have been published by Zwally and others (1989) for the entire Greenland ice sheet, by Herzfeld and others (1997) for the Lambert Glacier/Amery Ice Shelf region of Antarctica, and by Bindschadler (1984) for the Jakobshavn Isbræ area. In this paper we take a different approach to the study of changes in ice sheets and their possible dependence on climatic change, which (a) utilizes the variable ice surface roughness rather than absolute elevation, and (b) studies the ice sheet in a sensitive area, a part of the ablation area, and (c) at high resolution. The Glacier Roughness Sensor (GRS) is used to measure surface roughness directly on the ice, to provide subscale information for satellite data and to study micromorphologic processes on the ice surface.

Ice surface roughness is an important parameter in the 


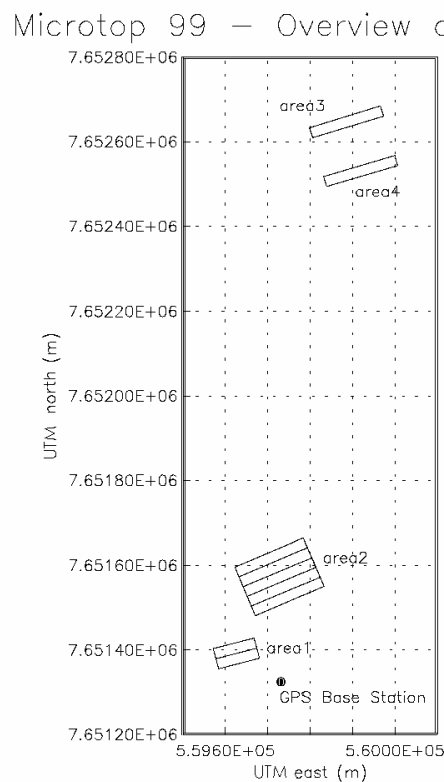

Microtop 99 - area3 and area4

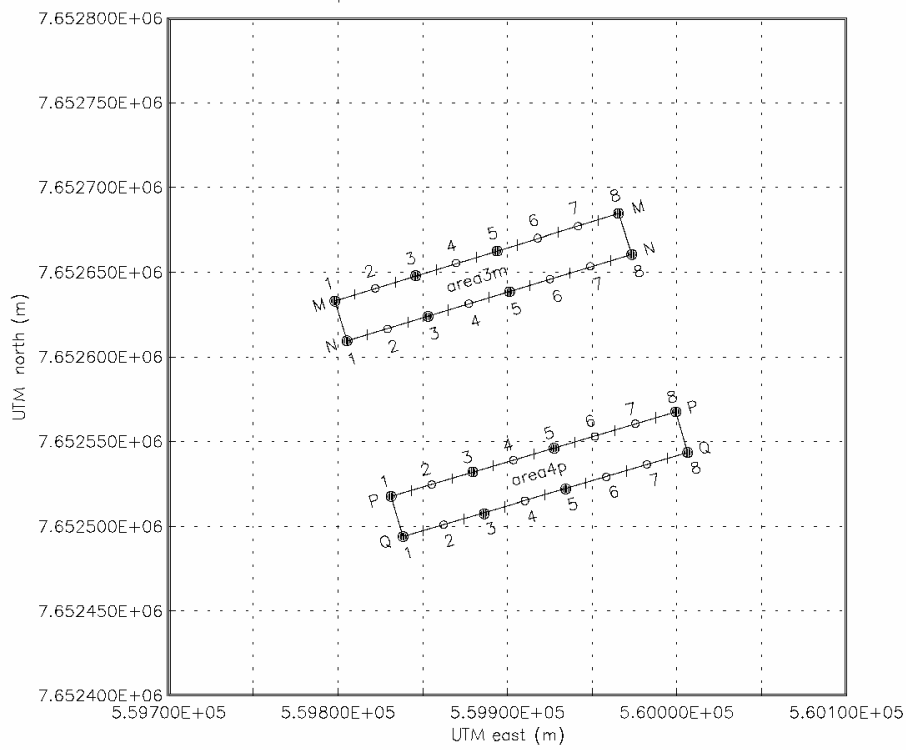

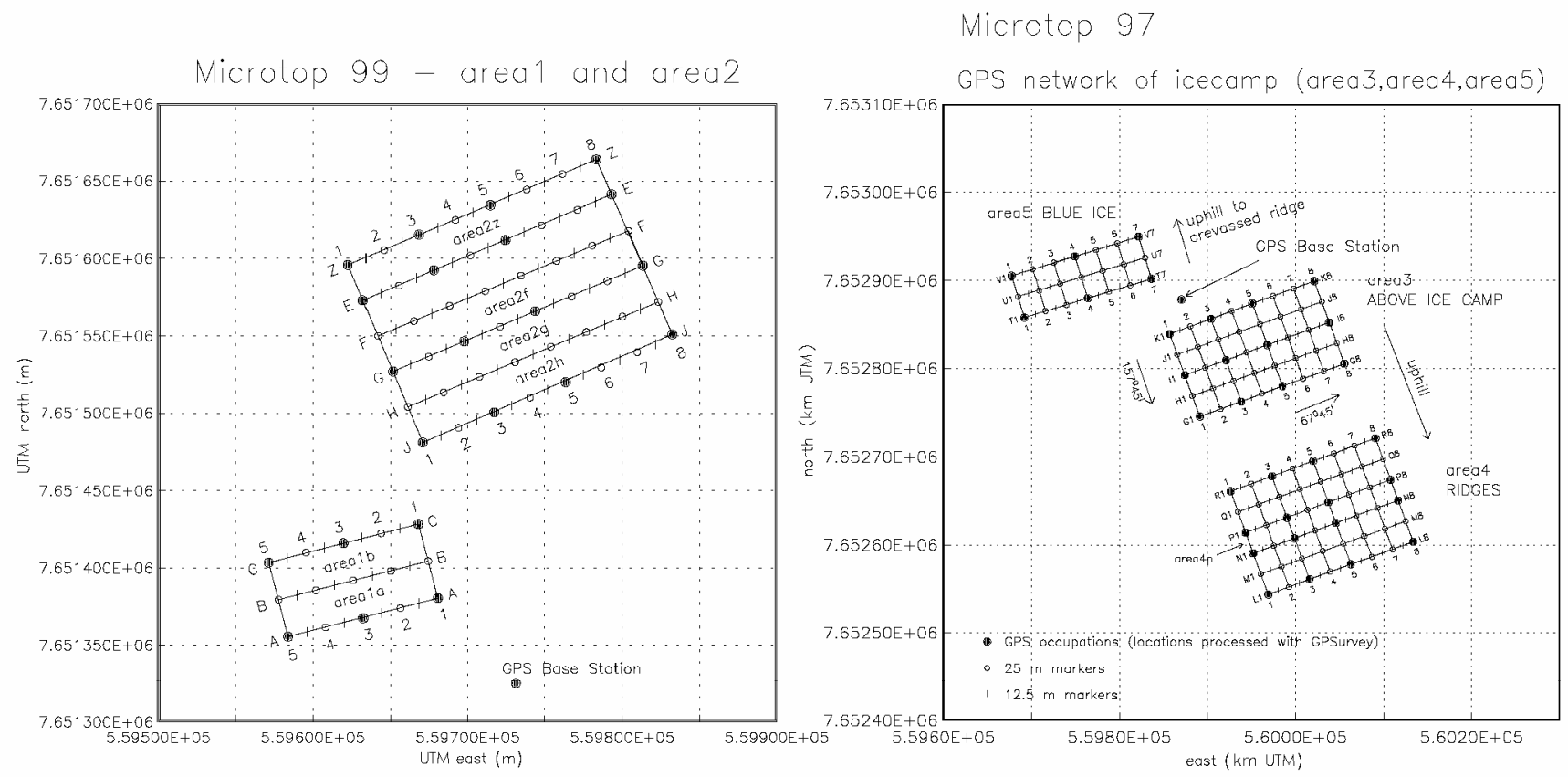

Fig. 1. GPS networks of MICROTOP97 and MICROTOP99 experiments, Jakobshavn Isbre drainage basin, West Greenland. GRS data collected in tracks in the survey areas shown. 1997 GPS base station is in ICECAMP97; 1999 base station is in ICECAMP99.

study of ablation processes and their changes, as the energy available for melting varies by a factor of 2 with surface roughness changes (Herzfeld and others, in press). Here, we describe measurements and analyses of surface roughness in the ablation area of Jakobshavn Isbræ drainage basin, in a seasonal comparison of the spring and summer ice surface.

\section{STUDY AREA}

Jakobshavn Isbræ and its drainage basin is an ideal location for the study of both dynamically and climatically induced changes in the Greenland ice sheet. Jakobshavn Isbræ is the world's fastest-moving ice stream; it starts on the Greenland Inland Ice and accelerates to $7 \mathrm{~km} \mathrm{a}^{-1}\left(19 \mathrm{~m} \mathrm{~d}^{-1}\right.$; Echelmeyer and others, 1991) or $20.6 \mathrm{~m} \mathrm{~d}^{-1}\left(7.519 \mathrm{~km} \mathrm{a}^{-1}\right.$; Pelto and others, 1989) at the calving front. Faster-moving ice can be traced for $80 \mathrm{~km}$ up the ice sheet for the longer, wavy south- ern branch (south ice stream), which joins the shorter north ice stream along a feature called "the zipper" because of the pattern of merging crevasses (Echelmeyer and others, 1991). Surface velocity in the flow direction is about $1000 \mathrm{~m} \mathrm{a}^{-1}$ $50 \mathrm{~km}$ upstream of the calving front (Iken and others, 1993). Ice thickness at the calving front is about $800 \mathrm{~m}$, as can be told from floating icebergs that have turned to the side. The ice stream follows a geological trough that continues in the ice fjord. The adjacent slower-moving ice (we measured a maximum directional velocity of approximately $0.3 \mathrm{~m} \mathrm{~d}^{-1}$ ) has a surface morphology that is dominated by wind, snowfall and ablation processes. In the slowmoving part south of the south ice stream, measurements of surface roughness were carried out during expeditions MICROTOP97 and MICROTOP99 as part of a larger project to study ice-surface properties from satellite and with field data (for MICROTOP97 see, e.g., Herzfeld and others, 2000a, b). 


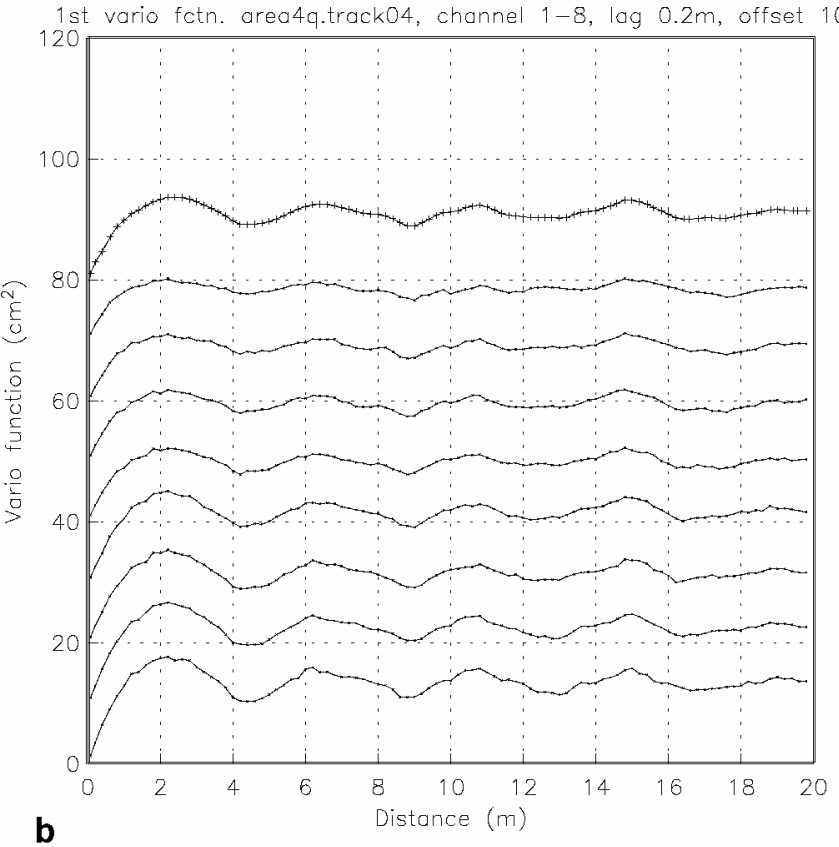

a

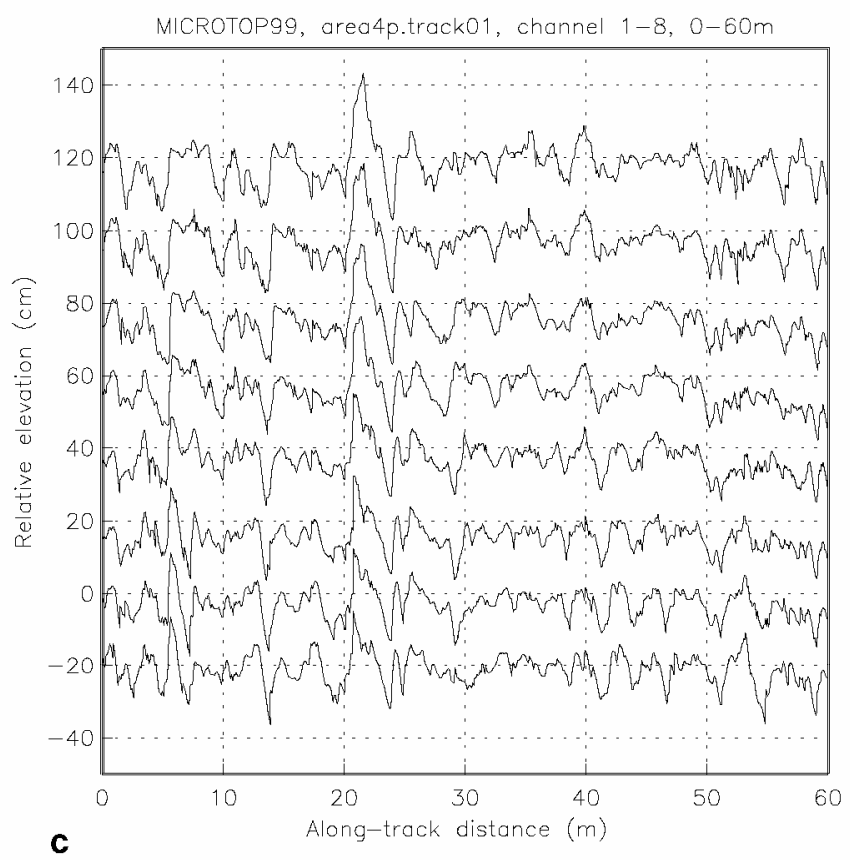

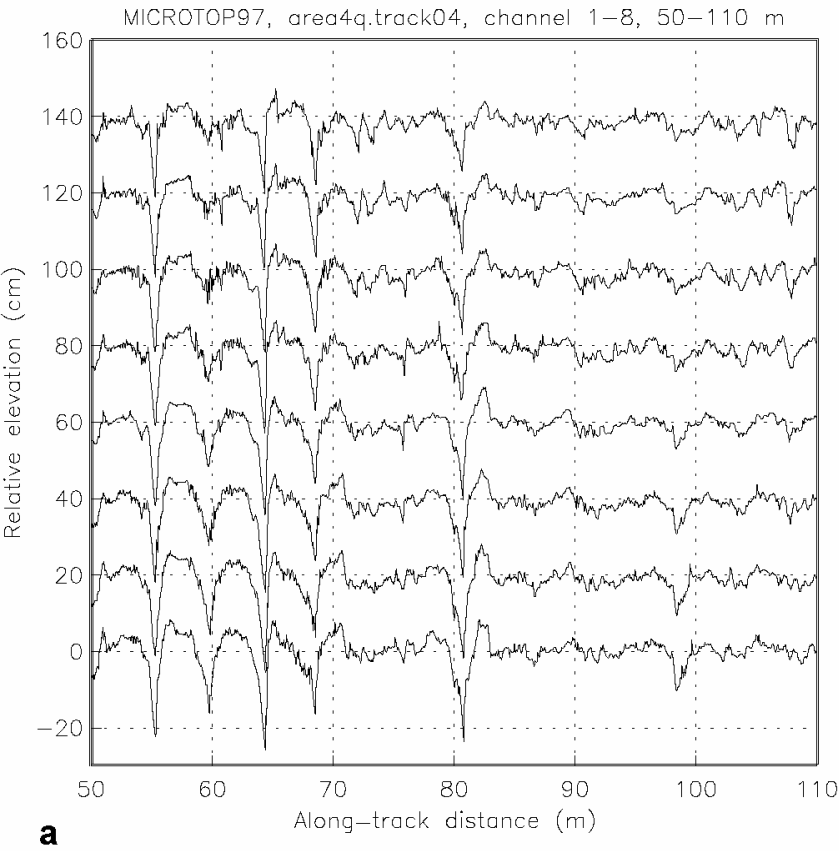

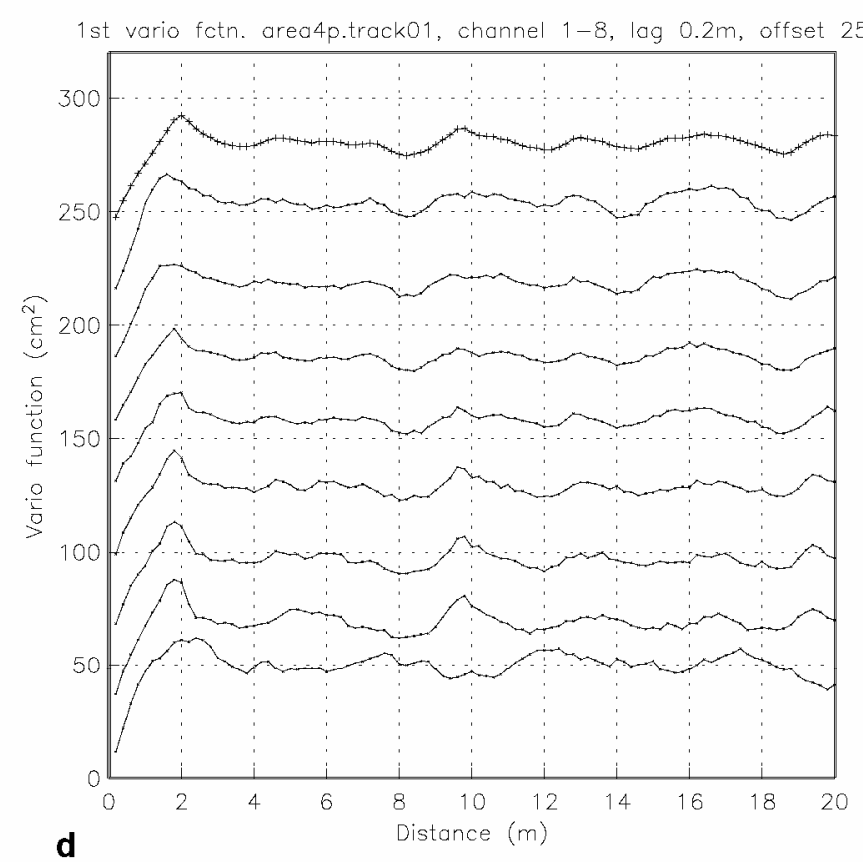

Fig. 2. Seasonal comparison of GRS data over ice surfaces and corresponding vario functions for simple ice-surface types. Area4 "RIDGES", characterized by large meltwater ridge-and-valley systems, Jakobshavn Isbre drainage basin. (a, b) Spring (May) 1997, dataset area4q.track04 (a4q04), simple morphology of ablation ridges with old snow. (c, d) Summer (July) 1999, dataset area4p.track01 (a4p01.99), simple morphology of molten-out ablation ridges. For location, see survey grids in Figure 1. Left panels: GRS surface roughness profiles (typical section): relative elevation corrected for along-track position, plotted with offset $0.2 \mathrm{~m}$. Right panels: vario functions calculated from GRS data in corresponding left panels. Notice units on vario-function axis in both plots, which indicate that summer surface is rougher than spring surface.

Morphologic properties at any scale are not captured by absolute elevation (above an imaginary zero reference, such as sea level) but rather by changes of elevation in space, in mathematical terms $\mathrm{d} h / \mathrm{d} x$, where $h$ is elevation and $x$ location. At larger scale this is topographic relief, at small scale roughness. So, ice surface roughness is a morphologic characteristic of ice surfaces.

\section{INSTRUMENTATION AND SURVEY SET-UP}

Surface roughness data were collected with the GRS, an instrument designed specifically for the survey of micro- topography/roughness of snow and ice surfaces at $\mathrm{cm}$ to $100 \mathrm{~m}$ scales. The GRS is a towed instrument that surveys surface roughness in swath mode with $0.1 \mathrm{~m}$ along-track spacing, $0.2 \mathrm{~m}$ across-track spacing and sub-centimeter accuracy. The GRS works mechanically with electronic registration. The instrument consists of a $2 \mathrm{~m}$ by $2 \mathrm{~m}$ large sled frame supporting eight survey arms (eight channels) that are hinged on a main crossbar and touch the ground. As the sled is pulled across the ice, the survey arms move freely over the surface, with their ends following the ups and downs of microtopography. Angular motion of each arm is registered digitally with a frequency of $10 \mathrm{~Hz}$. If the sled is pulled at $1 \mathrm{~m} \mathrm{~s}^{-1}$ velocity, this translates into $0.1 \mathrm{~m}$ along-track spacing of observations. 
Differential global positioning system (GPS) data, obtained by an antenna and receiver integrated in the GRS and coregistered during survey, provide locational reference, and clinometer data are available for correction for instrument motion if necessary. The instrument itself, repeatability of measurements, accuracy, error levels and the influence of new snow are described and analyzed in Herzfeld and others (1999).

During MICROTOP97 and MICROTOP99 expeditions, GRS surveys were carried out in survey grids of $175 \mathrm{~m}$ by multiples of $25 \mathrm{~m}$, which were staked out using classic surveying methods (Fig. 1). The size of the survey areas was determined under the constraints that (1) they are large enough to contain sufficiently many repetitions of characteristic morphologic features, (2) small enough to be morphologically homogeneous, (3) large enough to encompass several synthetic aperture radar (SAR) data pixels which may show some variability, and (4) small enough to be covered by a man-hauled instrument in a reasonable time. Surveying approximately normal to the general strike of the dominant morphologic structures allows a saving in width of the area and thus in total survey time. Correlation lengths/spatial frequencies can then easily be determined from vario functions of track data. Spatial covariation is higher in all other directions, and highest in the across-track direction. Time data (times of network marker passes of the GRS) are also recorded manually and provide a back-up for locational correction. The vario functions analyzed here are processed from time-data-corrected files.

\section{ANALYSIS METHOD: GEOSTATISTICAL SURFACE GLASSIFICATION}

The analysis method utilized to obtain ice-surface-morphologic characteristics is geostatistical surface classification (Herzfeld and others, 2000a). In investigations of surface roughness, we study properties of the spatial derivative of surface elevation, or (micro) topography. In the same way that topographic relief and landforms (rather than elevation) are the objective of morphology at a large scale, surface roughness is the variable that captures micromorphologic processes.

The analytically defined spatial derivative needs to be calculated numerically from a dataset. One way to do this is by building differences of elevation values over given distances. Forming the (mathematical) limit of such expressions, for distance increments approaching zero, yields the value of the surface slope in a given location:

$$
\lim _{x \rightarrow x_{0}} \frac{z\left(x_{0}\right)-z(x)}{x_{0}-x} .
$$

This approach gives a local slope value, the slope at point $x_{0}$. If we are interested in characteristics of the surface (in a given area (e.g. the study area)) then the actual slope value at each location is not relevant. Parameters that describe the morphology a bit more generally and are valid for the whole study area are more valuable. Therefore, we form differences of elevation values again, but average over all points that have the same common distance (or distance and direction), according to:

$$
v_{1}(h)=\frac{1}{2 n} \sum_{i=1}^{n}\left[z\left(x_{i}\right)-z\left(x_{i}+h\right)\right]^{2}
$$

for pairs of points $\left(x_{i}, z\left(x_{i}\right)\right),\left(x_{i}+h, z\left(x_{i}+h\right)\right) \in \mathcal{D}$, where $\mathcal{D}$ is a region in $\mathcal{R}^{2}$ (case of survey profiles) or $\mathcal{R}^{3}$ (case of survey areas) and $n$ is the number of pairs sepa- rated by a distance, or lag, $h\left(\in\right.$ : element of; $\mathcal{R}^{2}, \mathcal{R}^{3}$ : twoand three-dimensional space of real numbers (coordinates), respectively). The function $v_{1}(h)$ is called the first-order vario function. If we let the values of the first-order vario function take the place of the data in Equation (2), we can calculate the second-order vario function $v_{2}$. This may be repeated to obtain vario functions of higher order (Herzfeld, 2002; Herzfeld and others, 2003), which are particularly useful in snow and ice surface analysis. Note that formally, but not mathematically, $v_{1}$ corresponds to the sample variogram, but for the variogram generalization is not possible.

Vario functions are calculated from GRS data, separately for each of the eight GRS survey channels and jointly for all channels (see Fig. 2). (In a joint vario function, pairs as in Equation (2) are drawn from data of all channels.) Parameters characteristic of surface features are calculated from the vario functions (see the following definitions and equations), and a feature vector is composed of the parameters. Discrimination algorithms are applied to extract and combine features and associate them to an ice-surface class; the algorithms may be deterministic (e.g. Herzfeld and Higginson, 1996) or follow the connectionist association of neural networks (Herzfeld and Zahner, 2001). Surface characterization, classification or segmentation may be performed. Characterization results in a unique description of each surface class. Classification is the assignment of objects (which may be previously unknown to the system) to a surface class, based on the characterization of surface classes. Segmentation of an entire region may be obtained by application of the classification as a moving-window operator to a large spatial dataset.

The mainstay of this paper is the application of these methods to derive characteristics of seasonal changes in the ice surface morphology of the Jakobshavn Isbræ ablation area from MICROTOP97 expedition (spring) data and new previously unpublished MICROTOP99 expedition (summer) data. The parameters that are most useful in the seasonal comparison are:

\section{The pond parameter}

\section{Parameter-type-1 (ptl) parameters (slope parameters)}

Parameter-type-2 (pt2) parameters (relative significance parameters).

Maximum vario-function value (pond parameter) is the simplest parameter; it is used to distinguish flat areas from areas with morphologic (micro) relief. For instance, the vario function of an evenly spaced hill-and-valley profile in topography is a sinusoidal wave. Then the lag to the first minimum $\min _{1}$ (after the first maximum $\max _{1}$ ) in the sine curve is the characteristic spacing of hills and valleys in the topographic relief. To distinguish pure hill--valley sequences from overprinted ones and to characterize more complex morphologic structures, significance parameters are introduced (Fig. 3):

Parameter-type-2 (pt2) parameters are relative significance parameters; in this paper, we use:

$$
\mathrm{p} 2=\operatorname{pt} 2\left(\max _{1}, \min _{1}\right)=\frac{\gamma_{\max _{1}}-\gamma_{\min _{1}}}{\gamma_{\max _{1}}}
$$

and p3 $=\mathrm{pt} 2\left(\max _{1}, \min _{2}\right), \mathrm{p} 4=\mathrm{pt} 2\left(\max _{2}, \min _{2}\right), \mathrm{p} 5=\mathrm{pt} 2$ $\left(\max _{\mathrm{s}}, \min _{2}\right), \mathrm{pl} 0=\mathrm{pt} 2\left(\max _{1}, \min _{3}\right)$, where $\max _{i}, \min _{j}$ denote local maxima and minima in the vario function (here: $v_{1}$ ) for $i \leq j, h_{x}$ is the lag, and $\gamma_{x}$ the vario-function value for $h_{x}$ ( $x$ stands for any subscript); $\max _{\mathrm{s}}$ is the greater of $\max _{1}$ and $\max _{2}$. 

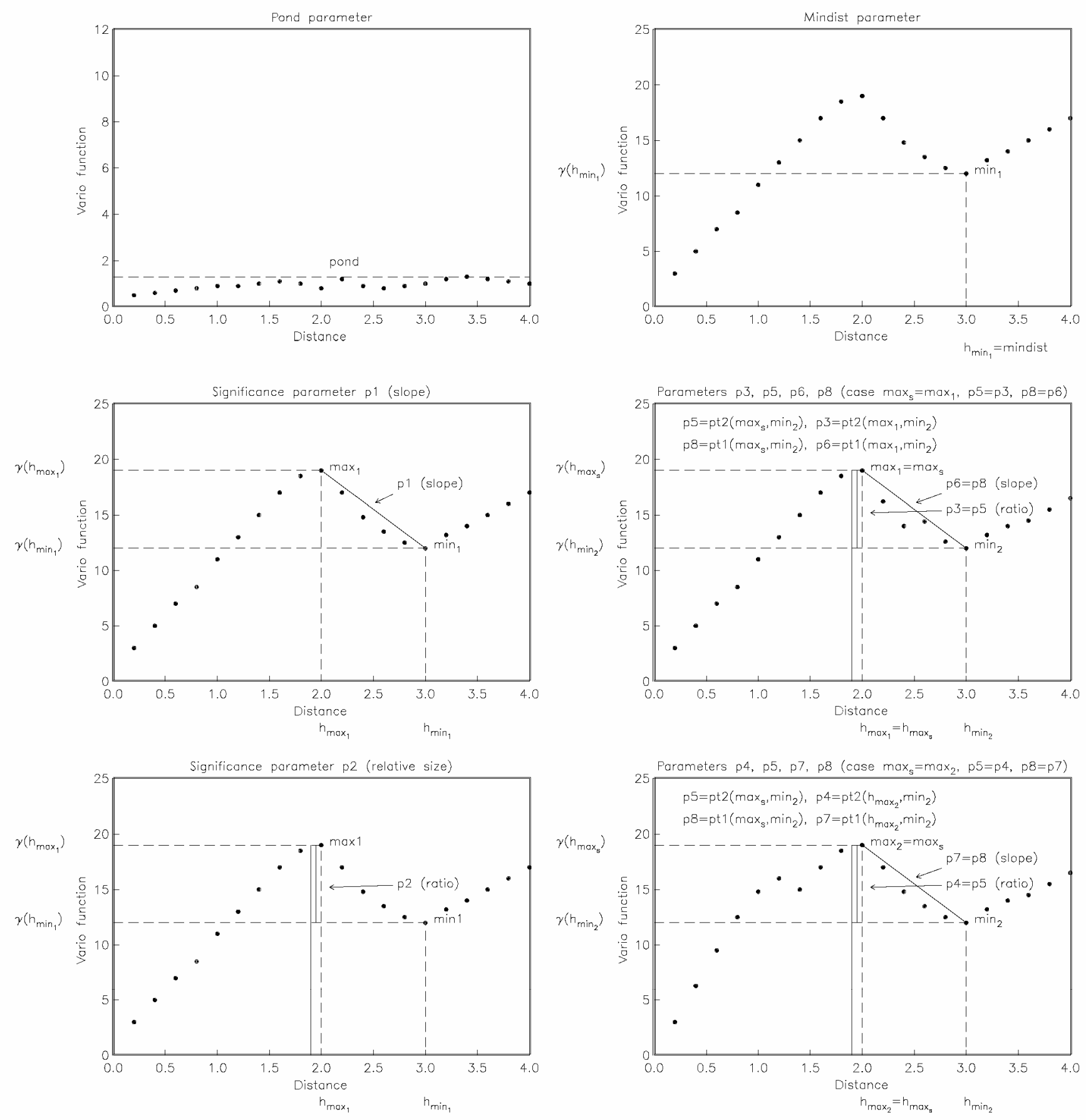

Fig. 3. Sketch of geostatistical classification parameters.

Parameter-type-1 (ptl) parameters are slope parameters; here, we use:

$$
\mathrm{p} 1=\operatorname{pt} 1\left(\max _{1}, \min _{1}\right)=\frac{\gamma_{\max _{1}}-\gamma_{\min _{1}}}{\left|h_{\max _{1}}-h_{\min _{1}}\right|}
$$

as well as $\mathrm{p} 8=\operatorname{ptl}\left(\max _{\mathrm{s}}, \min _{2}\right)$ and $\mathrm{pl} 4=\operatorname{ptl}\left(\max _{1}, \min _{3}\right)$. To avoid catching noise rather than features, vario functions may be filtered, depending on application and scale, prior to automated feature detection (Herzfeld and Higginson, 1996).

\section{EXPEDITIONS MICROTOP97 AND MICROTOP99}

During expedition MICROTOP97 (May, June 1997), GRS surveys were carried out in the Jakobshavn Isbræ drainage basin in the ablation area, south of the south ice stream. Survey areas area3, area 4 and area 5 are located in the vicinity of ICECAMP97 (68 $58.712^{\prime} \mathrm{N}, 49^{\circ} 30.280^{\prime} \mathrm{W}$; $864 \mathrm{~m}$ a.s.l.).
Camp was set up just outside of the heavily crevassed area, south of the marginal area of the south ice stream, as determined by reconnaissance and video-survey flights in 1996. A shallow crevassed ridge in the ice separates the camp from the heavily crevassed areas to the north, but thin and closed crevasses continue in the ice in survey areas area4 and area5. The camp lies in a shallow depression between a ridge in the north and higher areas in the south. ICECAMP99 was located south of the higher and somewhat crevassed area south of ICECAMP97. The location of ICECAMP99 was at $68^{\circ} 57.979^{\prime} \mathrm{N}, 49^{\circ} 30.519^{\prime} \mathrm{W}$ (about $1.5 \mathrm{~km}$ south of ICECAMP97; see Fig. 1). Areas area 3 and area4 are the same in both expeditions (see Fig. 1) and so are suitable for a seasonal comparison.

\section{Ice surface morphology}

The entire area3 slopes gently down to the north, in the 

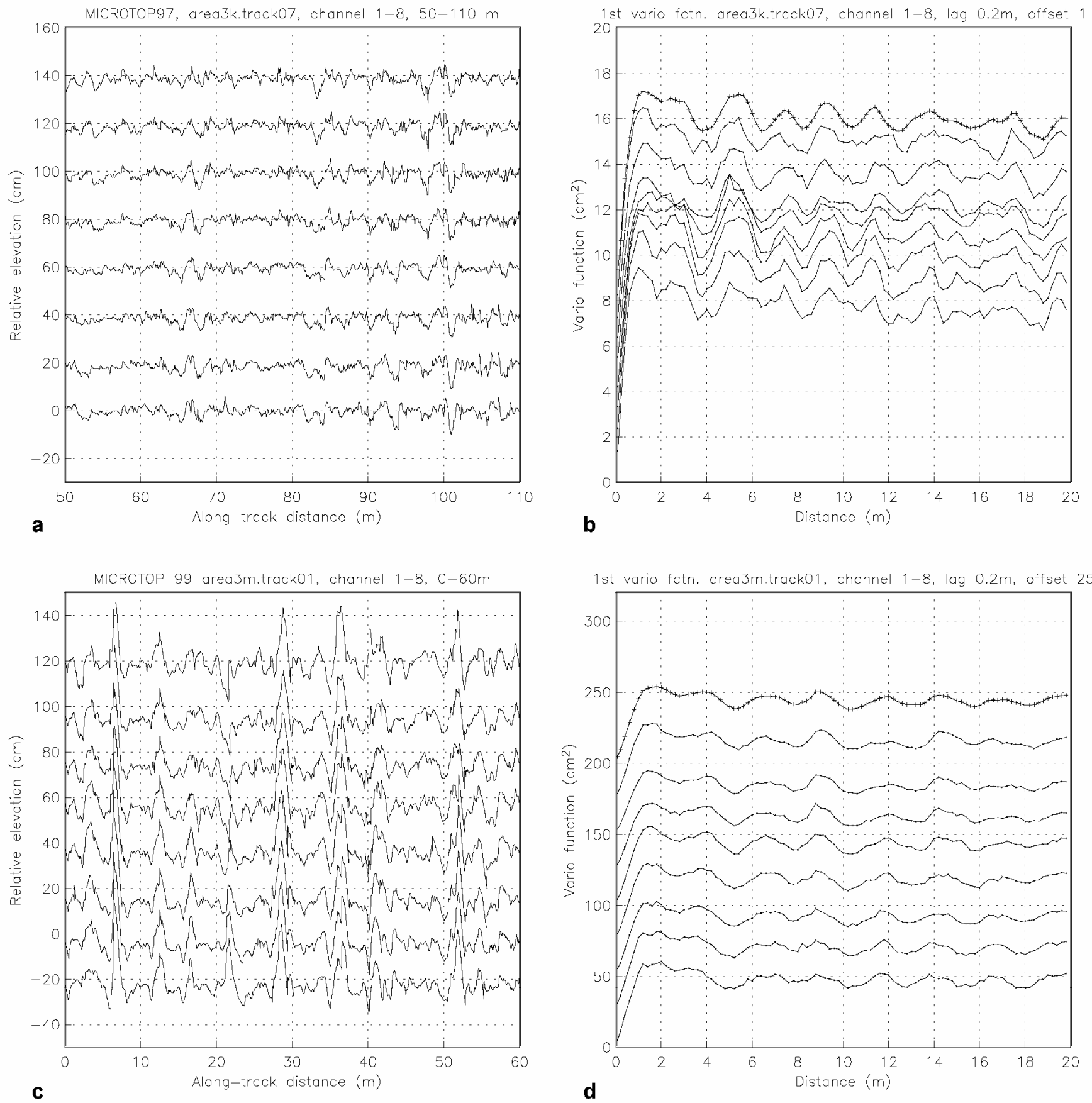

Fig. 4. Seasonal comparison of GRS data and corresponding vario functions for a complex ice surface type. Area3 "ABOVE ICECAMP”, Jakobshavn Isbre drainage basin. For location, see survey grids in Figure 1. (a, b) Spring (May) 1997, dataset area3k.track07 (a3k07): ice surface with ridges and ridge segments generated by melting and refreezing with sastrugi in valleys inside segments (complex morphology). (c, d) Summer (July) 1999, dataset area3m.track01 (a3m01.99) (complex morphology with ablation structures of different sizes, overall higher roughness of molten-out surface). Left panels: GRS surface roughness profiles (typical section ): relative elevation corrected for along-track position, plotted with offset $0.2 \mathrm{~m}$. Right panels: vario functions calculated from GRS data in corresponding left panels. Notice units on vario-function axis in both plots, which indicate that summer surface is rougher than spring surface.

general direction of the south ice stream. There is a rise of about $0.8-1.0 \mathrm{~m}$ from line $\mathrm{K}$ to line $\mathrm{I}$, and about $1.4-2.0 \mathrm{~m}$ from line I to line $\mathrm{G}$. The area falls about $0.5 \mathrm{~m}$ from $\mathrm{K} 1$ to K8. The morphology is similar in area3 and area4. The entire area4 (RIDGES) consists of elongated near-parallel ridges, which have a gently wavy trend, and also slopes down to the north. The ridge systems are clearly generated by melting, not by wind (see analysis in next section). In spring 1997, the height of the ridges increased in the uphill direction from area3 to area4 and throughout area4 to $\approx 1 \mathrm{~m}$ in area $4 \mathrm{r}$ and area $4 \mathrm{q}, \approx 2 \mathrm{~m}$ in area $4 \mathrm{p}$, and to $\approx 2.5 \mathrm{~m}$ in area $4 \mathrm{n}$ and area $4 \mathrm{~m}$; the flanks steepened to $>45^{\circ}$ in area $4 \mathrm{n}$ and area $4 \mathrm{~m}$. The snow had sublimation structures with a $5 \mathrm{~cm}$ spacing, and a hard surface with about $5 \mathrm{~mm}$ of new snow, at the time of survey 1 (area4pl, on 28 May 1997); at the time of survey 2 (area4p2, area $4 n$, area $4 m$, on 28 May 1997) the new snow cover was $2 \mathrm{~cm}$, and the surface was softening in the valleys. At the time of survey 3 on 29 May 1997 (area4p3, area4q, area4r) there were about 10 $\mathrm{cm}$ of fresh snow from precipitation of a storm the night before.

There are also blue-ice areas (developing into melt ponds) 
Table 1. Geostatistical parameters calculated from GRS data of West Greenland ice surfaces

\begin{tabular}{|c|c|c|c|c|c|c|c|c|c|c|c|c|c|c|c|}
\hline GRSdata & Area & Surface type & mo-year & pond & $h_{\max _{1}}$ & $\gamma_{\max _{1}}$ & $h_{\min _{1}}$ & $\gamma_{\min _{1}}$ & $h_{\max _{2}}$ & $\gamma_{\max _{2}}$ & $h_{\min _{2}}$ & $h_{\max _{3}}$ & $\gamma_{\max _{3}}$ & $h_{\min _{3}}$ & $\gamma_{\min _{3}}$ \\
\hline $\mathrm{a} 3 \mathrm{k} 07$ & ICECAMP & $\begin{array}{l}\text { Complex (ablation, } \\
\text { sastrugi) }\end{array}$ & 5-1997 & 9.300 & 1.200 & 9.300 & 2.000 & 8.700 & 2.400 & 8.800 & 2.800 & 3.000 & 8.700 & 3.800 & 7.600 \\
\hline a3m01.99 & ICECAMP & Complex (ablation features) & $7-19995$ & 55.000 & 1.800 & 55.000 & 2.800 & 48.000 & 3.800 & 50.000 & 5.200 & 6.600 & 48.000 & 7.800 & 38.000 \\
\hline a4q04 & RIDGES & Ridges & $5-1997$ & 14.000 & 2.200 & 14.000 & 4.200 & 10.000 & 6.400 & 13.000 & 9.000 & 10.800 & 12.800 & 13.200 & 11.000 \\
\hline a4p01.99 & RIDGES & Ridges & 7-1999 9 & 90.000 & 2.000 & 90.000 & 3.600 & 70.000 & 4.600 & 80.000 & 5.600 & 6.000 & 78.000 & 6.600 & 75.000 \\
\hline alb210.99 & RUNNELS & Complex (runnels, holes) & $7-19993$ & 36.000 & 1.600 & 36.000 & 3.400 & 31.000 & 4.400 & 32.000 & 5.400 & 7.600 & 33.000 & 9.000 & 27.000 \\
\hline a $2 g 01.99$ & BIOSTREAMS & Complex (streams, ridges) & 7-1999 4 & 46.000 & 2.000 & 46.000 & 4.000 & 38.000 & 5.200 & 42.000 & 6.800 & 8.200 & 40.500 & 9.000 & 39.000 \\
\hline GRSdata & Area & Surface type & mo-year & $\mathrm{p} 2$ & p3 & $\mathrm{p} 4$ & p5 & $\mathrm{p} 10$ & $\mathrm{pl}$ & p8 & pl4 & & & & \\
\hline $\mathrm{a} 3 \mathrm{k} 07$ & ICECAMP & $\begin{array}{l}\text { Complex (ablation, } \\
\text { sastrugi) }\end{array}$ & 5-1997 & 0.065 & 0.065 & 0.011 & 0.065 & 0.183 & 0.750 & 0.375 & 0.654 & & & & \\
\hline a3m01.99 & ICECAMP & Complex (ablation features) & 7-1999 & 0.127 & 0.345 & 0.280 & 0.345 & 0.309 & 7.000 & 5.588 & 2.833 & & & & \\
\hline $\mathrm{a} 4 \mathrm{q} 04$ & RIDGES & Ridges & 5-1997 & 0.286 & 0.300 & 0.246 & 0.300 & 0.214 & 2.000 & 0.618 & 0.272 & & & & \\
\hline a4p01.99 & RIDGES & Ridges & 7-1999 & 0.222 & 0.155 & 0.050 & 0.155 & 0.167 & 12.500 & 3.889 & 3.268 & & & & \\
\hline alb210.99 & RUNNELS & Complex (runnels, holes) & 7-1999 & 0.139 & 0.194 & 0.094 & 0.194 & 0.250 & 2.778 & 1.842 & 1.216 & & & & \\
\hline a $2 \mathrm{~g} 01.99$ & BIOSTREAMS & Complex (streams, ridges) & 7-1999 & 0.174 & 0.185 & 0.107 & 0.185 & 0.152 & 4.000 & 1.771 & 1.000 & & & & \\
\hline
\end{tabular}

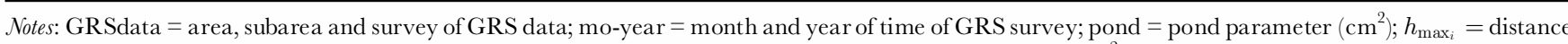
to $i$ th maximum in vario function of GRS data $(\mathrm{m}) ; \gamma_{\max _{i}}=$ vario-function value at $i$ th maximum $\left(\mathrm{cm}^{2}\right) ; h_{\min _{i}}=$ distance to $i$ th minimum in vario function of GRS data $(\mathrm{m}) ; \gamma_{\min _{i}}=$ vario-function value at $i$ th maximum $\left(\mathrm{cm}^{2}\right) ; \mathrm{p} i=$ geostatistical classification parameter

in the vicinity, where water following a ridge-and-valley pattern down from a shallow ridge induces a pattern in the blueice area and creates an alternation of mostly frozen and daily melting/refreezing patches in May 1997 (see, e.g., area5, Herzfeld and others, 1999). The spring areas are described in Herzfeld and others $(1999,2000 \mathrm{a})$. Areas area 3 and area 4 are the same in both expeditions (see Fig. 1) and so are suitable for a seasonal comparison. Markers from 1997 were relocated in 1999. (GPS coordinates do not match exactly, however, because they were differentially corrected to each year's base stations, rather than to the International Geodetic Network. This is preferable here, because GPS data accuracy increases over short baselines, as required in the microtopographic study.)

\section{SEASONAL COMPARISON AND RESULTS ON ICE- SURFAGE-MORPHOGENETIC PROGESSES}

MICROTOP97 took place in May and earlyJune, with latespring conditions on the Inland Ice in the ablation area of Jakobshavn Isbræ. During MICROTOP99, parts of area3 and area 4 were resurveyed in summer conditions in the second half of July. In late spring, the ice surface is still covered by compacted, wet and refrozen snow, and occasionally by fresh snow. Fortunately, during MICROTOP97 a storm with heavy snowfall occurred after part of the surveying had been completed, so by resurveying after the snowfall we were able to investigate the effect of fresh snow on the GRS data and the vario-function parameters (Herzfeld and others, 1999). Repeat studies on the reproducibility of surveys of the same area were carried out during MICROTOP97; if surveys are undertaken under the same conditions, the results (and ensuing vario-function parameters) are almost the same (Herzfeld and others, 1999). Consequently, it is justified to attribute differences between spring and summer surface variograms to seasonal changes in the surface morphology.
In summer (July 1999) the ice surface was completely bare of snow, molten out and saturated with water almost to the surface level. The ice surface was much rougher than in May 1997. In the variogram of area4q (RIDGES) (Fig. $2 \mathrm{~d}$ ), this is reflected in the overall higher variogram values (note that the maximal variogram value is $\approx 14$ in Figure $2 b$ and $\approx 60$ in Figure 2 d; the maximal value on the $\gamma$ axis is 120 in Figure $2 b$ and 320 in Figure $2 d$ ) and steeper slopes. The pond parameter reflects the difference between spring and summer surfaces: the overall roughness across the surveyed scales is highest in area4 in summer (pond is 90 compared to 14 in spring), and also much higher for area3 (pond $=55$ in summer compared to 9.3 in spring). Of the significance parameters, the slope parameter $\mathrm{pl}=\operatorname{ptl}\left(\max _{1}, \min _{1}\right)$ captures the difference between spring and summer surfaces best: for area $3, \mathrm{pl}=0.75$ in spring and $\mathrm{pl}=7$ in summer; for area $4, \mathrm{pl}=2$ in spring and $\mathrm{pl}=12.5$ in summer; this clear difference is a result of the increased roughness relative to the spacing of the characteristic surface features.

In area3, a complex morphology of ridges and valleys, similar to that in area4, but of smaller relief, interspersed with flat areas, is observed. In May 1997, small sastrugi had formed in the low spots. In spring, the complexity of the surface in area3 shows in the fact that the most significant $\max -\min$ sequence is $\max _{1}$ to $\min _{3}$, because the subordinate surface features cause the intermediate minima $\left(\min _{1}, \min _{2}\right)$ of lower significance; the values related to $\max _{1}$ and $\min _{3}$ are: $10=p t 2\left(\max _{1}, \min _{3}\right)=0.309$ and $\mathrm{p} 14=\operatorname{pt} 1\left(\max _{1}, \min _{3}\right)=2.833($ see Fig. 4 ; Table 1$)$.

In summer 1999, the larger features are still present (characterized in the vario function by a subordinate minimum followed by a significant minimum), whereas the increased small-scale roughness causes increased overall vario-function values (Fig. 4b). The vario function of the summer surface in area3 has one subordinate minimum less than the vario function of the spring surface (Fig. $4 \mathrm{~d}$ and b), because the sastrugi in the valleys between the ridges have disappeared; the most significant $\max -\min$ sequence is $\max _{1}-\min _{2}$ with 
pt2 $\left(\max _{1}, \min _{2}\right)=\mathrm{p} 3=\mathrm{p} 5=0.345$ (Fig. 4d). In a comparison across seasons, we compare the largest pt 2 values, so the summer value is slightly higher than the spring value $(0.345$ compared to 0.309).

In area4, in spring the ice surface was characterized by very evenly spaced and sized ridges and valleys (Fig. 2). Here, melting led to an increased complexity of surface forms ( $\mathrm{p} 2=0.222$ in summer compared to 0.286 in spring); the large ridges are still the dominant features in this area $(\mathrm{p} 2=\mathrm{pt} 2$ $\left(\max _{1}, \min _{1}\right)$ is the largest $\mathrm{pt} 2$ value, and the associated spacing is approximately the same (3.6 $\mathrm{m}$ in summer compared to $4.2 \mathrm{~m}$ in spring)). The location of tracks is not exactly the same in both surveys. This means that the large ridge--valley system exists throughout several seasons (for at least 2 years). In conclusion, the ice surface in the ablation area undergoes seasonal changes that show in particular in the smaller-scale features, whereas the large ( $4 \mathrm{~m}$ spaced, up to $2 \mathrm{~m}$ high) features remain throughout several years. From comparison with analysis of area3 data, it follows that melting is a more dominant ice-surface-morphogenetic process than wind, as small sastrugi are at times observed between ridges, but disappear later in the year. The relief of the ridge-and-valley systems may increase as the result of a self-enhancing process, in an interplay of snowfall, wind and melting, with a dominance of surficial melting.

\section{CONCLUSIONS}

In a seasonal comparison of data from spring (May 1997) and summer (late July 1999), characteristic parameters of the spring and summer ice surface were calculated, and as a result, an answer to the morphogenetic question of ice surface processes could be derived. In this part of the Jakobshavn Isbræ drainage basin, ice surface structures develop in an interplay of ablation, refreezing, snowfall, wind and (distant) crevassing. Characteristic parameters associated with each of these processes can be identified in the variograms and utilized in ice-surface characterization. It follows that (a) features of a scale of one to several meters remain characteristic throughout at least several years, and (b) seasonally dependent characteristics or, more technologically, the influence of lack of snow, degree of melting, or small-scale surface roughness, may be discriminated. An open question in the glaciologic community was the relative importance of the morphogenetic processes. A result of our work is that ablation is the dominant morphogenetic process in this part of the drainage basin, and likely at other locations at the same elevation. The ablation ridges are the dominant features that remain over several seasons, and melting occurs each spring with the same characteristic spacing, induced by the location of pre-existing ridges and valleys.

\section{AGKNOWLEDGEMENTS}

Thanks to the University NAVSTAR Consortium for the loan of GPS receivers and solar panels in 1997; to S. Böhm, R. Keller, B. Rothstein, M. Mimler, M. Auras, T. Erbrecht, R. Stosius andJ. Erickson, of Universität Trier, Germany, for help with surveying; to the pilots and crews of Grønlandsfly for flight support and hospitality in the Ilulissat Airport cargo hall; and to the Ilulissat Tourist Office staff for help with logistics. Work was supported by the Deutsche Forschungsgemeinschaft under grants DFG Hel547/4 and DFG He1547/8 and in part by the U.S. National Aeronautics and Space Administration Office of Polar Programs under contracts NAGW-3790 and NAG5-6114. Many thanks to C. S. M. Doake for valuable comments on the manuscript.

\section{REFERENGES}

Alley, R. B. and I. M. Whillans. 1991. Changes in the West Antarctic ice sheet. Science, 254(5034), 959-963.

Bindschadler, R. A. 1984. Jacobshavns Glacier drainage basin: a balance assessment. 7. Geophys. Res., 89(C2), 2066-2072.

Clarke, G. K. G., U. Nitsan and W. S. B. Paterson. 1977. Strain heating and creep instability in glaciers and ice sheets. Rev. Geophys. Space Phys., 15(2), 235-247.

Echelmeyer, K., T. S. Clarke and W. D. Harrison. 1991. Surficial glaciology of Jakobshavns Isbræ, West Greenland: Part I. Surface morphology. $\mathcal{F}$. Glaciol., 37(127), 368-382.

Herzfeld, U. C. 2002. Vario functions of higher order - definition and application to characterization of snow surface roughness. Comput. Geosci., 28(5), 641-660.

Herzfeld, U. C. and C. A. Higginson. 1996. Automated geostatistical seafloor classification - principles, parameters, feature vectors, and discrimination criteria. Comput. Geosci., 22(1), 35-52.

Herzfeld, U. C. and O. Zahner. 2001. A connectionist-geostatisticalapproach to automated image classification, applied to the analysis of crevasse patterns in surging ice. Comput. Geosci., 27(5), 499-512.

Herzfeld, U. C. and 6 others. 1997. Monitoring changes of ice streams using time series of satellite-altimetry-based digital terrain models. Math. Geol., 29(7), 859-890.

Herzfeld, U. C., H. Mayer, W. Feller and M. Mimler. 1999. Glacier roughness surveys of Jakobshavns Isbrae drainage basin, West Greenland, and morphological characterization. Z. Gletscherkd. Glazialgeol., 35(2), 117-146.

Herzfeld, U. C., H. Mayer, W. Feller and M. Mimler. 2000a. Geostatistical analysis of glacier-roughness data. Ann. Glaciol., 30, 235-242.

Herzfeld, U. C., M. Stauber and N. Stahl. 2000b. Geostatistical characterization of ice surfaces from ERS-1 and ERS-2 SAR data, Jakobshavn Isbræ, Greenland. Ann. Glaciol., 30, 224-234.

Herzfeld, U. C., J. E. Box, K. Steffen, H. Mayer, N. Caine and M.V. Losleben. In press. A case study on the influence of snow and ice surface roughness on melt energy. Z. Gletscherkd. Glazialgeol.

Herzfeld, U. C., H. Mayer, N. Vaine, M. Losleben and T. Erbrecht. 2003. Morphogenesis of typical winter and summer snow surface patterns in a continental alpine environment. Hydrol. Processes., 17, 619-649.

Hughes, T. 1973. Is the West Antarctic ice sheet disintegrating? 7. Geophys. Res., 78(33), 7884-7910.

Huybrechts, P. 1993. Glaciological modelling of the Late Cenozoic East Antarctic ice sheet: stability or dynamism? Geogr. Ann., 75A(4), 221-238.

Iken, A., K. Echelmeyer, W. Harrison and M. Funk. 1993. Mechanisms of fast flow in Jakobshavns Isbræ, West Greenland: Part I. Measurements of temperature and water level in deep boreholes. F. Glaciol., 39(131), 15-25.

Krabill, W. and 8 others. 1999. Rapid thinning of parts of the southern Greenland ice sheet. Science, 283(5407), 1522-1524.

Meier, M. F. 1984. Contribution of small glaciers to global sea level. Science, 226(4681), 1418-1421.

Pelto, M. S., T.J. Hughes and H. H. Brecher. 1989. Equilibrium state of Jakobshavns Isbræ, West Greenland. Ann. Glaciol., 12, 127-131.

Schubert, G. and D. A. Yuen. 1981. Initiation of ice ages by creep instability and surging of the East Antarctic ice sheet. Nature, 292(5853), 127-130.

Steffen, K. and J. Box. 2001. Surface climatology of the Greenland ice sheet: Greenland Climate Network 1995-99. F. Geophys. Res., 106(D24), $33,951-33,964$.

Zwally, H.J., A. C. Brenner, J. A. Major, R. A. Bindschadler and J. G. Marsh. 1989. Growth of Greenland ice sheet: measurement. Science, 246(4937), 1587-1589. 